\title{
Pathologic T3a renal cell carcinoma: a classification in need of further refinement
}

\author{
John M. DiBianco ${ }^{1}$, Patrick T. Gomella ${ }^{2}$, Mark W. Ball ${ }^{2}$ \\ ${ }^{1}$ Department of Urology, George Washington University Medical School, Washington DC, USA; ${ }^{2}$ Urologic Oncology Branch, National Cancer \\ Institute, National Institutes of Health, Bethesda, MD, USA \\ Correspondence to: Mark W. Ball, MD. Urologic Oncology Branch, Center for Cancer Research, National Cancer Institute, Building 10, Room 1-5940, \\ Bethesda, MD 20892, USA. Email: mark.ball@nih.gov. \\ Provenance: This is an invited Editorial commissioned by Section Editor Xiao Li (Department of Urology, Jiangsu Cancer Hospital \& Jiangsu \\ Institute of Cancer Research \& Nanjing Medical University Affiliated Cancer Hospital, Nanjing, China). \\ Comment on: Shah PH, Lyon TD, Lohse CM, et al. Prognostic evaluation of perinephric fat, renal sinus fat, and renal vein invasion for patients with \\ pathological stage T3a clear-cell renal cell carcinoma. BJU Int 2018. [Epub ahead of print].
}

Submitted Dec 14, 2018. Accepted for publication Dec 18, 2018.

doi: 10.21037/atm.2018.12.51

View this article at: http://dx.doi.org/10.21037/atm.2018.12.51

Kidney cancer is associated with a significant global disease burden $(1,2)$. Although mortality rates for renal cell carcinoma (RCC) in the United States remain stable, the incidence of RCC continues to rise, largely due to increased incidental detection on routine abdominal imaging $(1,3)$. Ultimately, both treatment recommendations and patient prognosis are based on the stage of disease $(4,5)$. Pathologic staging of RCC continues to be refined, especially for the characterization of pathologic T3a (pT3a) disease, which represents locally advanced disease with invasion of the fat or vasculature of the kidney (Figure 1), and is associated with worse oncologic outcomes compared to organ confined disease $(6,7)$.

A pathologic consensus statement from the International Society of Urologic Pathology (ISUP) in 2012 leads to several changes to $\mathrm{pT} 3 \mathrm{a}$ in the most recent $8^{\text {th }}$ edition release of the American Joint Committee on Cancer (AJCC) (8). These changes included removal of the term "grossly" from the description of renal vein (RV) involvement, "segmental veins" replaced "muscle containing" and the addition of pelvicalyceal invasion was added. Thus, the current definition of T3a disease is a tumor that extends into the $\mathrm{RV}$ or its segmental branches, or invades the pelvicalyceal system, or invades perirenal and/or renal sinus fat (RSF) but not beyond Gerota's fascia (8) (Figure 2).

A recent study, titled "Prognostic evaluation of perinephric fat, renal sinus fat, and renal vein invasion for patients with pathological stage T3a clear-cell renal

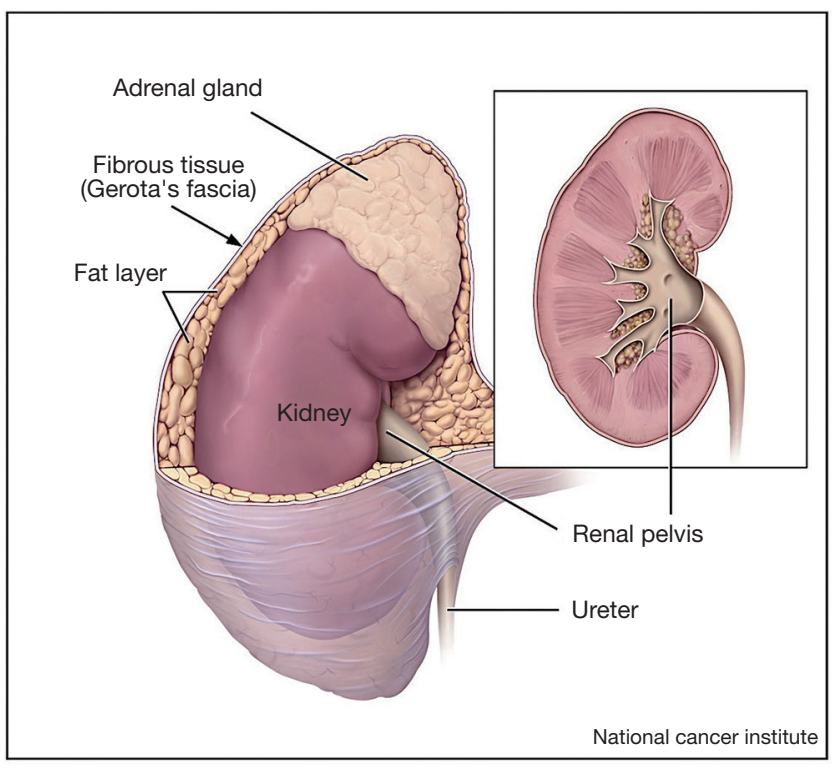

Figure 1 Kidney anatomy. National Cancer Institute, Alan Hoofring (Illustrator), 2004.

cell carcinoma" by Shah et al. investigated the prognostic significance of various patterns of extrarenal extension within the categorized T3a for clear-cell renal cell carcinoma (ccRCC) (9). Specifically, they investigated the prognostic significance of invasion of perirenal fat (PF), RSF and RV and/or a combination of these 

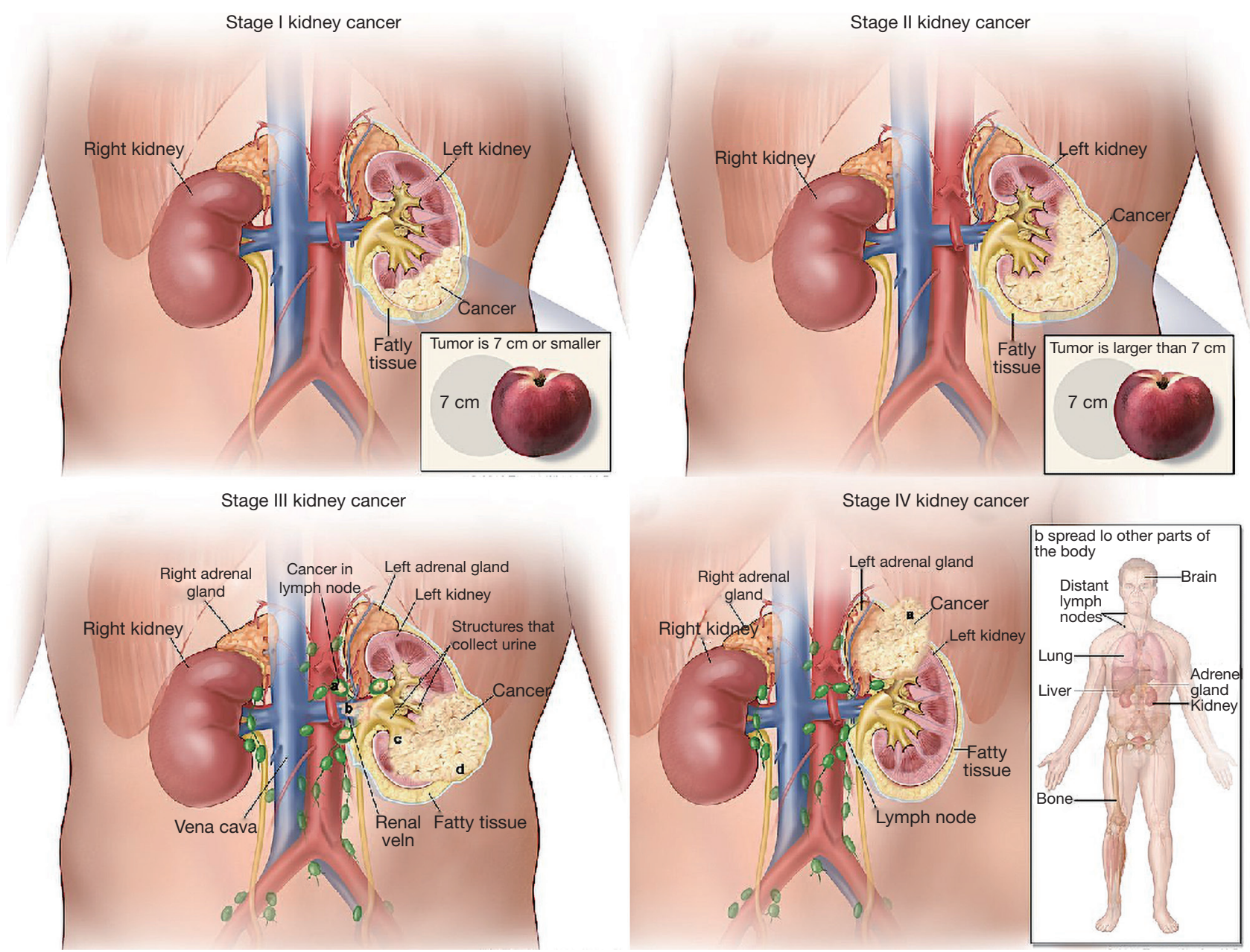

Figure 2 Kidney cancer staging. Modified from National Cancer Institute, Terese Winslow, 2018.

variables. The authors identified patients who underwent radical nephrectomy between 1970 and 2011 who were diagnosed at pT3a, pNX/0, M0 clear cell RCC utilizing an institutional registry. A total of 563 patients were identified and progression-free survival, cancer specific survival and overall survival were analyzed. They found that while individually tumor PF, RSF, or RV invasion did not differ significantly in oncologic outcomes, tumors found to have a combination of such invasion portended a worse prognosis than those with singular sites. This finding was associated with a 2.66 -fold increase in cancer specific mortality. They conclude that their findings may help to refine riskstratification of non-metastatic T3a RCCs to better inform patient prognosis and clinical trial enrollment (9).

While this manuscript is a valuable contribution to the literature, several points should be considered. First, the median tumor size in this study was $9 \mathrm{~cm}$, meaning that even in the absence of fat or venous invasion, these tumors were at least clinical T2a (cT2a). The significance of pT3a upstaging may differ between cT2a and lower staged tumors. Additionally, these tumors were treated with radical nephrectomy. The significance of these features in the partial nephrectomy population may be different. For these reasons, these results may not be generalizable to patients with either smaller tumors or those who undergo partial nephrectomy. Patients who undergo partial nephrectomy typically have tumors that are smaller, more peripherally located and less complex than those in which radical nephrectomy is undertaken (5).

The decision to perform radical or partial nephrectomy for T2 tumors may be based on multiple patient factors, such as age and comorbidities, as well as tumors factors like 
size, RENAL nephrometry score and tumor location (10). Recently, partial nephrectomy has increased in utilization, particularly for larger more complex tumors, although the decision $(5,11)$.

Due to the increased interest in adjuvant systemic therapy, patient specific and disease stratification may be increasingly studied in years to come. Both tumor genetics and staging may be integral to patient follow up strategies, surveillance and possible systemic treatments (12-14). The authors of the current study (Shah et al.) propose their findings may help to refine risk-stratification, however, the recommended follow up surveillance strategy for stage 3 disease is not altered due to substages $(12,15)$. Currently, the follow up strategy only is altered by the upstaging to stage 4 disease.

Several studies have examined the outcomes of partial nephrectomy for T3a tumors with results demonstrating equal to acceptable oncological outcomes when compared to radical nephrectomy $(5,16)$. Gorin et al. examined the clinical outcomes of patients who underwent partial nephrectomy for clinical stage T1 or T2 disease who were then upstaged to T3a on pathological examination (16). They found that approximately $10 \%$ of these patients experienced either local or distant disease recurrence, however they did not substratify for the differences between PF, RSF, or RV invasion (16). Ball et al. compared outcomes of segmental RV invasion versus main RV invasion and found that main RV invasion portended worse diseasespecific and overall survival (6). Taken together, these studies indicate that the current definition of pT3a kidney cancer may be too broad as there is significant heterogeneity of clinical outcomes in this group. Larger, multi-center studies may be helpful in clarifying how future staging schema may be more predictive of oncologic outcomes.

\section{Acknowledgements}

This research was supported (in part) by the Intramural Research Program of the National Cancer Institute, NIH.

\section{Footnote}

Conflicts of Interest: The authors have no conflicts of interest to declare.

\section{References}

1. American Cancer Society. Cancer Facts \& Figures 2018.
Atlanta: American Cancer Society, 2018.

2. Klaassen Z, Jen RP, DiBianco JM, et al. Factors associated with suicide in patients with genitourinary malignancies. Cancer 2015;121:1864-72.

3. Kabaria R, Klaassen Z, Terris MK. Renal cell carcinoma: links and risks. Int J Nephrol Renovasc Dis 2016;9:45-52.

4. Ljungberg B, Bensalah K, Canfield S, et al. EAU guidelines on renal cell carcinoma: 2014 update. Eur Urol 2015;67:913-24.

5. Campbell S, Uzzo RG, Allaf ME, et al. Renal Mass and Localized Renal Cancer: AUA Guideline. J Urol 2017;198:520-9.

6. Ball MW, Gorin MA, Harris KT, et al. Extent of renal vein invasion influences prognosis in patients with renal cell carcinoma. BJU Int 2016;118:112-7.

7. Thompson RH, Leibovich BC, Cheville JC, et al. Is renal sinus fat invasion the same as perinephric fat invasion for pT3a renal cell carcinoma? J Urol 2005;174:1218-21.

8. Trpkov K, Grignon DJ, Bonsib SM, et al. Handling and staging of renal cell carcinoma: the International Society of Urological Pathology Consensus (ISUP) conference recommendations. Am J Surg Pathol 2013;37:1505-17.

9. Shah PH, Lyon TD, Lohse CM, et al. Prognostic evaluation of perinephric fat, renal sinus fat, and renal vein invasion for patients with pathological stage T3a clear-cell renal cell carcinoma. BJU Int 2018. [Epub ahead of print].

10. An JY, Ball MW, Gorin MA, et al. Partial vs Radical Nephrectomy for T1-T2 Renal Masses in the Elderly: Comparison of Complications, Renal Function, and Oncologic Outcomes. Urology 2017;100:151-7.

11. Ghani KR, Sukumar S, Sammon JD, et al. Practice patterns and outcomes of open and minimally invasive partial nephrectomy since the introduction of robotic partial nephrectomy: results from the nationwide inpatient sample. J Urol 2014;191:907-12.

12. Capogrosso P, Capitanio U, La Croce G, et al. Followup After Treatment for Renal Cell Carcinoma: The Evidence Beyond the Guidelines. Eur Urol Focus 2016;1:272-81.

13. Ricketts CJ, Linehan WM. The origin, evolution and route to metastasis of clear cell RCC. Nat Rev Nephrol 2018;14:538-540.

14. Linehan WM, Ricketts CJ. Kidney cancer in 2016: RCC - advances in targeted therapeutics and genomics. Nat Rev Urol 2017;14:76-8. 
15. Motzer RJ, Jonasch E, Agarwal N, et al. Kidney Cancer, Version 2.2017, NCCN Clinical Practice Guidelines in Oncology. J Natl Compr Canc Netw 2017;15:804-34.

16. Gorin MA, Ball MW, Pierorazio PM, et al. Outcomes

Cite this article as: DiBianco JM, Gomella PT, Ball MW. Pathologic T3a renal cell carcinoma: a classification in need of further refinement. Ann Transl Med 2018;6(Suppl 2):S133. doi: 10.21037/atm.2018.12.51 and predictors of clinical T1 to pathological T3a tumor up-staging after robotic partial nephrectomy: a multiinstitutional analysis. J Urol 2013;190:1907-11. 